\title{
Evaluation of the performance of replaceable particulate and powered air-purifying respirators considering non-recommended wearing methods
}

\author{
Shingo SEKOGUCHI ${ }^{1}$, Taiki SHIRASAKA ${ }^{1}$, Hajime ANDO ${ }^{1}$, \\ Kazunori IKEGAMI ${ }^{1}$ and Akira OGAMI ${ }^{1}$ \\ ${ }^{1}$ Department of Work Systems and Health, Institute of Industrial Ecological Sciences, University of Occupational \\ and Environmental Health, Japan
}

Received March 23, 2020 and accepted August 24, 2020

Published online in J-STAGE August 29, 2020

\begin{abstract}
This study evaluated the performance of two respirators, a replaceable particulate respirator (RPR) and a powered air-purifying respirator (PAPR), worn according to non-recommended methods. Ten subjects wore either an RPR or PAPR according to the recommended method, or according to a non-recommended method, with a knit cover placed between the facepiece cushion and face, with a towel placed between the facepiece cushion and face, or with the headband on a helmet. The leakage rate of each wearing variation was then measured, according to the procedure for determining the protection factor of respiratory protective equipment, using atmospheric dust as required by JIS T8150. The average leakage rate for the RPR was $1.82-10.92 \%$, whereas that of the PAPR was $0.18-0.42 \%$. The performance of the RPR decreased when worn in methods outside of recommendations; however, there was no significant decrease in the performance of PAPR under any method of wear. Therefore, a PAPR is recommended for work in which a replaceable or disposable particulate respirator fails to provide sufficient protection against hazardous dust substances, or for workers who are unable to use a particulate respirator according to the recommended method owing to the work environment or health conditions.
\end{abstract}

Key words: Particulate respirator, Powered air-purifying respirator, Leakage rate, Respiratory disease, Occupational hygiene

\section{Introduction}

To prevent a variety of occupational respiratory diseases caused by hazardous dust substances, fundamental measures, such as engineering measures, should be prioritized. If these methods are not viable, measures should be taken to reduce exposure to hazardous dust substances. The

*To whom correspondence should be addressed.

E-mail: s-sekoguchi@med.uoeh-u.ac.jp

(C)2020 National Institute of Occupational Safety and Health particulate respirator is used in many workplaces wherein workers may be exposed to hazardous dust substances and is highly effective when used appropriately. The appropriate use of the particulate respirator is indicated by the circular notice: selection and use of a particulate respirator, issued by Japan Ministry of Health, Labour and Welfare (MHLW), Labour Standards Bureau ${ }^{1)}$, or The OSHA respiratory protection standard in Title 29 of the Code of Federal Regulations Part 1910.134 for General Industry (29 CFR 1910.134)2), among other standards.

However, a previous study revealed that workers in dust-generating occupations in Japan did not adhere to the 
recommended method of wearing the particulate respirator. Some regular users of particulate respirators placed fabric between the facepiece cushion and their face, whereas others wore the headband around a helmet ${ }^{3)}$. The circular notice of MHLW states that a particulate respirator should not be used by placing fabric between the facepiece cushion and face because of the risk of hazardous dust substances leaking into the facepiece ${ }^{1)}$. Moreover, 29 CFR 1910.134 states that the employer shall not permit respirators with tight-fitting facepieces to be worn by employees who have any condition that interferes with the face-tofacepiece seal or valve function ${ }^{2)}$. Non-recommended wearing methods may result in not only acute intoxication but also respiratory diseases such as pneumoconiosis and lung cancer, which develop over many years ${ }^{4,5)}$. In Japan, approximately 200 new cases of pneumoconiosis are diagnosed each year, although the number of individuals being diagnosed with pneumoconiosis and related symptoms is currently decreasing ${ }^{6}$.

Japanese laws and regulations state that a powered airpurifying respirator (PAPR) must be worn during certain work activities including tunnel construction, asbestos removal, and refractory ceramic fiber handling ${ }^{7-9)}$. Moreover, in 2018, MHLW published the Ninth Comprehensive Measures to Prevent Hazards Due to Dust report, which recommended the use of PAPR for work activities in addition to those described above ${ }^{10)}$. The PAPR provides a high level of protection because it filters the air to a safe level and eliminates leakages through the face seal ${ }^{11)}$. The high flow of air prevents the wearer from entraining contaminated ambient air ${ }^{11}$. Therefore, a PAPR has the potential to ensure adequate performance even if adhesion between the PAPR and the face is impaired-namely, if workers do not comply to the recommended wearing methods observed in the workplace that reduce adhesion between the particulate respirator and the face.

Several studies have been published on respirator performance; however, the majority have been performed on volunteers or health care workers using N95 filtering facepiece respirators ${ }^{12-17)}$. Although several studies have been published on the influence of facial hair ${ }^{18,19)}$, no previous studies have evaluated the performance of a respirator being worn by non-recommended methods. Therefore, this study aims to evaluate the performance of a replaceable particulate respirator (RPR) and a PAPR when they are being worn by non-recommended methods. This study also will clarify the combinations of particulate respirator type and wearing method that maintain an adequate performance.

\section{Methods}

\section{Study design and participants}

A crossover trial was conducted on ten subjects who provided informed consent prior to participation. Eligible participants were all healthy adults aged over 18 . To prevent contamination of tobacco dust while measuring the leakage rate, all participants were non-smokers. The subjects were recruited from the University of Occupational and Environmental Health, Japan, and the group was composed of eight men and two women. The average age (SD) for men was 32.1 (4.0) yr and for women 34.0 (5.0) yr. We prepared a combination of eight experimental patterns and assigned participants to a pattern using a random number table. The study was conducted at the artificial climate chamber of the University of Occupational and Environmental Health, Japan, during August and September in 2018. The artificial climate chamber was set to room temperature conditions $\left(20^{\circ} \mathrm{C}\right)$ with a relative humidity of $50 \%$.

\section{Particulate respirator}

The PAPR selected for testing was the BL-321S (Koken Ltd., Japan). The selected PAPR was tight-fitting, with a half facepiece and a breath-synchronized airflow system. The performances of this PAPR were as follows. Motor blower capacity: large airflow volume type (over $138 \mathrm{~L} /$ min), leakage rate: $\mathrm{B}$ class (less than 5.0\%), filtering efficiency: PL 1 (Over 95.0\%). The RPR selected for testing was 1180-05 (Koken Ltd., Japan). The filtering efficiency of this RPR was RL 2 (Over 95.0\%). This RPR consisted of a half facepiece and a single filter, a similar shape to BL-321S.

\section{Wearing variations}

The subjects wore either an RPR or a PAPR according to either the recommended method or one of the methods previously observed in the workplace ${ }^{3)}$. In a previous study, $39 \%$ of participants indicated that they placed something between the facepiece cushion and their face; a knit cover was the most commonly used item, followed by towels ${ }^{3)}$. Furthermore, $50 \%$ of participants reported that they wore the headband of the particulate respirator over a helmet ${ }^{3)}$. Therefore, four wearing methods were implemented in this study (Fig. 1): the recommended method (where the headband is placed on the area from the parietal region to the occipital region, with nothing between the facepiece cushion and the face) (R); K, where a knit cover is placed between facepiece cushion and the face; $\mathrm{T}$, where 
a towel is placed between the facepiece cushion and the face; and $\mathrm{H}$, where the headband is placed over a helmet.

\section{Measurement procedure}

In this study, the performance of the respirator was assessed by the leakage rate. The leakage rate was measured according to the procedure for the determination of protection factor of respiratory protective equipment using atmospheric dust provided by JIS T8150: the guidance for the selection, use, and maintenance of respiratory protective equipment $t^{20)}$.

Although the procedure for measuring the leakage rate was specified in JIS T8159: the procedure for measuring the leakage rate of respiratory protective equipment ${ }^{21)}$, it was technically and economically difficult to perform. Therefore, JIS T8150 was adopted in this study.

The measurement procedure of JIS T8150 was as follows (Fig. 2):

1) The measurer showed the subjects the relevant particulate respirator and explained how to put it on.

2) With the subjects wearing the particulate respirators, the measurer connected the particulate respirators to the measurement devices with the attached sampling tubes. The subjects adjusted the strap to find the optimal wearing position with minimal leakage. The measurer helped as appropriate.

3) The subjects wore the particulate respirator and performed five actions (normal breathing, deep breathing, turning head side-to-side, moving head up and down, and speaking). The subjects performed each action for $1 \mathrm{~min}$. The measurement device measured the concentration of atmospheric dust inside and outside the particulate respirator.

4) The measurer asked the subject questions related to their impression of the experiment, their physical condition, etc., before the measurement ended.

To minimize individual differences, the subjects wore the particulate respirator while looking in a mirror. The tightness of the strap was measured with a Sensor Interchangeable Amplifier (force gauge) (eZT, IMADA CO., LTD, Japan) and adjusted so that the force of the particulate respirator strap applied to the participants' head was approximately equal. The force of the lower strap applied to the participants' skin was adjusted to 1.0-2.0 Newton $(\mathrm{N})$.

\section{Calculation of leakage rate}

According to JIS T8150, the leakage rate was calculated by dividing the concentration within the particulate respi-
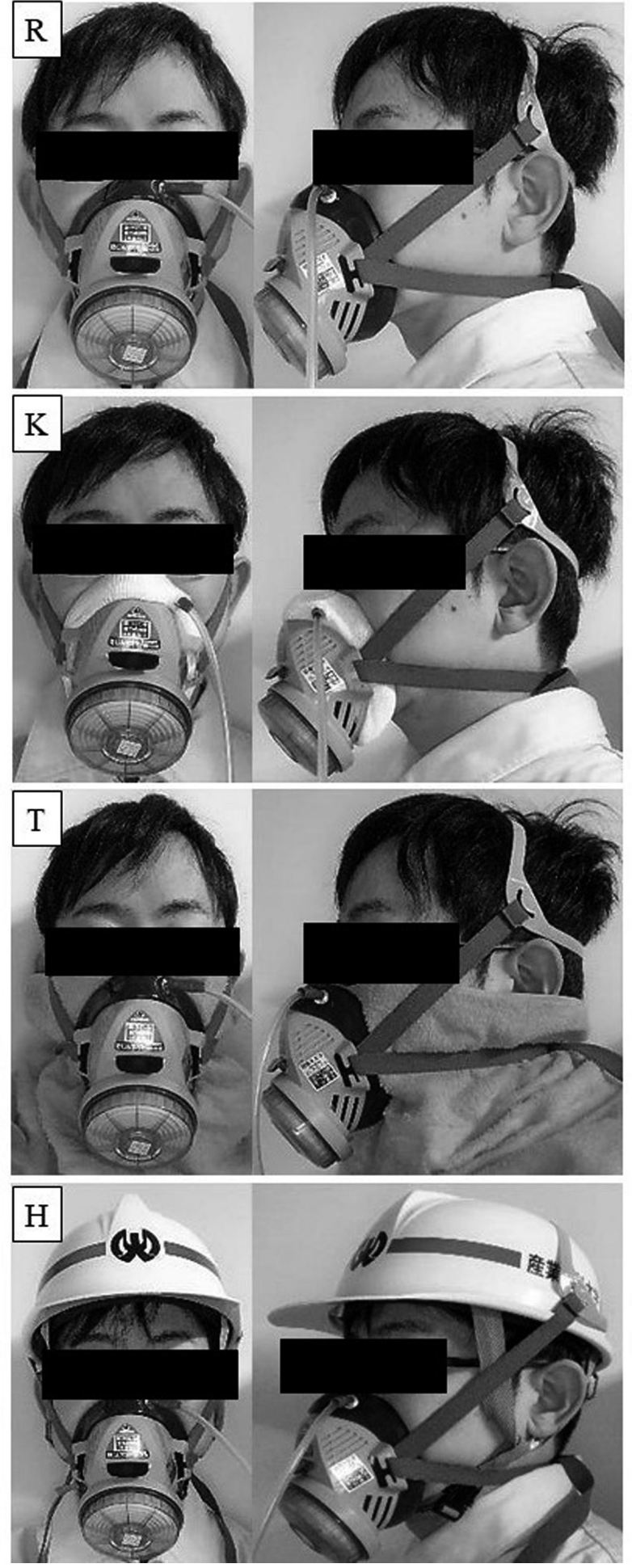

Fig. 1. Photographs depicting different wearing methods, using a replaceable particulate respirator as an example.

$\mathrm{R}$ : Recommended: the respirator headband is placed on the area from the parietal region to the occipital region, with nothing between the facepiece cushion and face. K: Knit: a knit cover is placed between the facepiece cushion and face. T: Towel: a towel is placed between the facepiece cushion and face. H: Helmet: the headband is worn over a helmet. 


\begin{tabular}{|c|c|c|c|c|c|c|c|c|}
\hline & \multicolumn{8}{|c|}{ Wearing variations } \\
\hline $\begin{array}{l}\text { Particulate } \\
\text { respirator }\end{array}$ & \multicolumn{4}{|c|}{$\begin{array}{l}\text { Replaceable Particulate Respirator } \\
\text { (RPR) }\end{array}$} & \multicolumn{4}{|c|}{$\begin{array}{l}\text { Powered Air-Purifying Respirator } \\
\text { (PAPR) }\end{array}$} \\
\hline $\begin{array}{l}\text { Wearing } \\
\text { methods }\end{array}$ & Recommended (R) & Knit (K) & Towel (T) & Helmet $(\mathrm{H})$ & Recommended (R) & Knit (K) & Towel (T) & Helmet $(\mathrm{H})$ \\
\hline & Normal breat & $\begin{array}{l}\text { easure the } \\
\lg \rightarrow \text { Dee }\end{array}$ & $\begin{array}{l}\text { akage rate } \mathrm{d} \\
\text { breathing } \rightarrow\end{array}$ & $\begin{array}{l}\text { Iring the foll } \\
\text { Turning hea }\end{array}$ & $\begin{array}{l}\text { ing actions (perfor } \\
\text { ide to side } \rightarrow \text { Movin }\end{array}$ & ed for $1 \mathrm{~m}$ & $\begin{array}{l}\text { each) } \\
\text { down } \rightarrow \mathrm{Sp}\end{array}$ & aking \\
\hline
\end{tabular}

Fig. 2. Outline of the study.

rator $(\mathrm{Ni})$ by the concentration outside of it $(\mathrm{No})^{20)}$ :

$$
\text { Leakage rate }=\mathrm{Ni} / \mathrm{No}^{*} 100(\%)
$$

The leakage rate of the five actions was measured for each wearing variation. Then, the arithmetic average of the leakage rates of the five actions was defined as the leakage rate of that wearing variation. For example, the average leakage rate for the PAPR worn according to the recommended method (R) was referred to as PAPR-R. All other leakage rates used the same notation format as previously described.

The leakage rate was measured using MT-03 (Sibata Scientific Technology Ltd., Japan). A widely-used OSHAaccepted quantitative fit testing has been primarily conducted previously using PortaCount (TSI Inc., USA), an instrument that measures the aerosol concentrations inside and outside the respirator using the principle of condensation nuclei counting ${ }^{22)}$. Unlike the PortaCount, the MT series utilizes an optical particle counting principle, based on the light scattering from aerosol particles ${ }^{22)}$. The light scattering can be described as follows ${ }^{23}$; sample air surrounded by sheath air that has been generated by passing through the HEPA filter is transferred to the detector where it is illuminated by a light beam (semiconductor laser) which is perpendicular to the direction of its path, resulting in the scattering of light. The magnitude of scattered light is proportional to the size of the particles. The scattered light is detected by a photodiode after being condensed by a lens. The intensity of the photocurrent in a pulse in proportion to the scattered light is compared with that obtained in the calibration using a polystyrene latex, with the diameter of standard particles being $0.7 \mu \mathrm{m}$. A previous study stated that the MT series adequately quantified a respirator $\mathrm{fit}^{22)}$.

The MT-03 quantified the air particles present inside and outside the particulate respirator sampled at $1 \mathrm{l} / \mathrm{min}$.
After measuring the air outside the particulate respirator for $17 \mathrm{~s}$, the instrument measured the air inside for $17 \mathrm{~s}$. The time taken for the dust remaining in the pipe at the start of the measurement to be replaced when switching the measurement path was set to $10 \mathrm{~s}$. Therefore, the full time required for one measurement was approximately $1 \mathrm{~min}$. The particles measured by the device were atmospheric dust with a particle size of at least $0.5 \mu \mathrm{m}$. During the measurement, incense sticks were burned to maintain a level of dust in the environment greater than the recommended sampling rate of 1,000 particles $/ 3 \mathrm{~s}$, for the MT03.

The concentration within the particulate respirator was measured by sampling the air inside the facepiece using a tube joint set fixed to both the sampling tube and particulate respirator. The concentration outside the particulate respirator was measured by sampling air using a sampling tube fixed with a string hung from the ceiling so that the end of it was close to the particulate respirator.

In this study, the allowable leakage rate was set to less than $5.0 \%$ in accordance to the specified leakage rate of the PAPR (B class).

\section{Statistical methods}

We used a linear mixed model (LMM), with the leakage rate (leakage rate for each action and each wearing variation) as the objective variable. Among the explanatory variables, the random factor was the survey participants and the fixed factors were participant sex, actions, wearing variations, and the interaction between the actions and wearing variations. We used the Bonferroni method for multiple comparisons. All statistical analyses were conducted using IBM SPSS advanced statistics 23.0. The significance level was set to 0.05 . 


\section{Ethics approval}

The ethics and informed consent procedure for this study were approved by the Ethics Committee of Medical Research, University of Occupational and Environmental Health, Japan (Receipt No. H30-058). Informed consent was obtained in writing from all participants.

\section{Results}

The main effect of the wear variation was its significant effect on the leakage rate $(\mathrm{F}[7,359]=36.26, p<0.001)$. On the other hand, participant sex $(\mathrm{F}[1,359]=1.058, p=0.304)$, actions $(\mathrm{F}[4,359]=0.977, p=0.420)$, as well as the interactions between the actions and the wearing variations $(\mathrm{F}[28$, $359]=0.418, p=0.997)$ did not have any significant effect on the leakage rate.

The RPR leakage rates for RPR-R, RPR-K, RPR-T, and RPR-H were $1.82 \%$ (range: $0.27-4.63 \%$ ), $10.92 \%$ (range: 5.15-26.05\%), 6.39\% (range: $3.19-13.17 \%$ ), and 3.19\% (range: $0.31-18.79 \%$ ), respectively. On the other hand, for PAPR-R, PAPR-K, PAPR-T, and PAPR-H, the PAPR leakage rates were $0.18 \%$ (range: $0.07-0.49 \%$ ), $0.23 \%$ (range: $0.07-1.08 \%$ ), $0.42 \%$ (range: $0.09-1.07 \%$ ), and $0.23 \%$ (range: $0.08-0.75 \%$ ), respectively. The $5 \%$ leakage rate (i.e., the allowable leakage rate range) was exceeded by $100 \%, 50 \%$, and $10 \%$ for RPR-K, RPR-T, and RPR$\mathrm{H}$, respectively; however, this value was zero for RPR-R, PAPR-R, PAPR-K, PAPR-T, and PAPR-H (Fig. 3).

Additionally, multiple comparisons of the leakage rates as a function of the wearing variation were made. The results obtained showed that the leakage rate of RPR-R was significantly lower than those of RPR-K and RPR-T $(p<0.001$ for both cases), while the leakage rate of RPR$\mathrm{K}$ was significantly higher than that of any other wearing methods $(p<0.001)$. Additionally, the leakage rate of RPR$\mathrm{T}$ was significantly higher than those of RPR-H $(p=0.014)$, PAPR-R, PAPR-K, PAPR-T, and PAPR-H $(p<0.001$ for the four cases), and the leakage rate of RPR-H was significantly higher than those of PAPR-R, PAPR-K, and PAPR-H ( $p=0.030, p=0.035, p=0.035$, respectively). Other combinations showed no significant differences.

\section{Discussion}

When using RPR according to the recommended method (RPR-R), the leakage rate was below 5\% (the allowable range of leakage rate), confirming that RPR was effective for the prevention of hazardous dust substances when used appropriately.

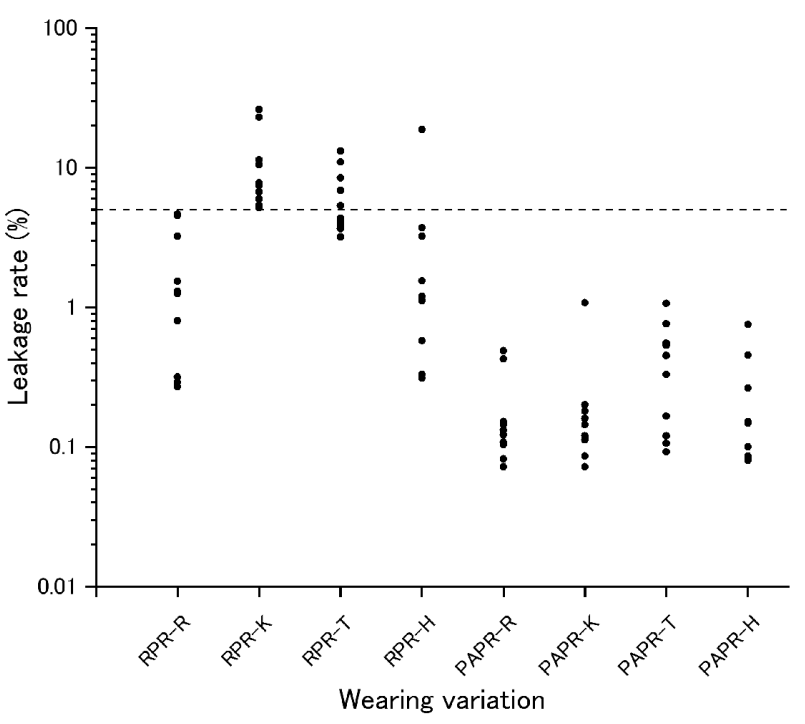

Fig. 3. Leakage rate of each wearing variation.

$(\mathrm{n}=10)$ Vertical axis shows the leakage rate (\%) and horizontal axis shows the wearing variations. Logarithmic scale on vertical axis is used to provide a clear presentation of results. The horizontal line on the graph indicates a leakage rate of $5.0 \%$. RPR: replaceable particulate respirator; PAPR: powered air-purifying respirator; -R: worn according to the recommended method; $-\mathrm{K}$ : worn with a knit cover between the facepiece cushion and face; $-\mathrm{T}$ : worn by placing a towel between the facepiece cushion and face; $-\mathrm{H}$ : worn with the headband on a helmet.

When using RPR with a knit cover or towel between the facepiece cushion and face (RPR-K and RPR-T), the leakage rate exceeded 5\%. Moreover, the leakage rate for prolonged use in the workplace is likely to be higher than that of this study. Thus, workers subject to these wearing variations could be exposed to hazardous dust substances. This result supports the circular notices of MHLW and 29 CFR 1910.134, which state that the particulate respirator should not be worn with a condition that interferes with the face-to-face piece seal ${ }^{1,2)}$.

There was no significant difference between the leakage rate when wearing the RPR with a helmet (RPR$\mathrm{H}$ ) and wearing the RPR according to the recommended method (RPR-R). However, this result may not accurately reflect workplace conditions as in this study, the strap was adjusted so that the force of the particulate respirator strap applied to the head was almost equal; however, in the workplace, the force of the strap on the skin is likely to be different for every individual. Thus, if the particulate respirator is not donned and adjusted correctly, the respirator fit may deteriorate due to the displacement of the headband. Additionally, as the headband is not made according to the shape and size of a helmet, the headband may slip off. This may also occur if a particulate respirator is worn with 
a helmet for a long period of time. Therefore, the leakage rate of wearing RPR with a helmet may not be as low as the results of this demonstrate in an actual workplace. Further research on this aspect is required; however, wearing RPR with a helmet is not currently recommended.

There are many reasons why workers wear respirators using methods outside the guided recommendations. For example, knit covers are used to reduce discomfort, such as pressure on the face ${ }^{3)}$. Towels are also used for this reason and for protection from the radiant heat of furnaces ${ }^{3)}$. Some workers may wear the headband on a helmet to reduce the difficulty of removal ${ }^{3)}$. With respect to knit covers, it has been reported that the absence of supervisors' instructions increases the use of $\mathrm{it}^{24)}$. The circular notice of MHLW states that employers shall provide workers with sufficient education and training on how to properly wear and use a particulate respirator and how to check the contact between the facepiece cushion and face ${ }^{1)}$. Moreover, 29 CFR 1910.134 states that the employer shall establish and implement a written respiratory protection program with worksite-specific procedures ${ }^{2}$. It has been reported that education regarding accurate respirator fit and usage resulted in improvements in the levels of leakage rate ${ }^{25}$. To prevent exposure to hazardous dust substances, it is necessary to ensure that sufficient education by the employer is provided.

When using a PAPR, the leakage rates of the three nonrecommended wearing methods were below $5 \%$. Compared to the average leakage rate for RPR worn according to the recommended method $(1.82 \%)$, those for the PAPR worn with a knit cover between the facepiece cushion and face $(0.23 \%)$, with a towel between the facepiece cushion and face $(0.42 \%)$, or with the headband on a helmet $(0.23 \%)$ were all lower. Because the inside of a PAPR is under positive pressure, it may be possible to maintain the performance of the respirator even if adhesion between the PAPR and the face is impaired. These results may be equally applicable to any PAPR with the same characteristics as the PAPR used in this study. The result of this study suggests that a PAPR may be more effective than an RPR for preventing a variety of occupational respiratory diseases. The use of a knit cover is permitted when there is a high risk of dermopathy and when the cover conforms to particulate respirator fitting requirements ${ }^{1}$. We suggest that PAPR should be used preferentially for work where a replaceable or disposable particulate respirator will not provide sufficient protection against hazardous dust substances, or for workers who have to use a knit cover and other adjustments because of the health conditions. Nota- bly, with the exception of work activities that require the use of a PAPR, few workers are using PAPR ${ }^{3)}$. One reason for this is that PAPR is more costly than replaceable or disposable particulate respirators. Therefore, further studies of the benefits that outweigh the cost disadvantages with regards to PAPR are required.

\section{Limitations and Future Research Directions}

This study has several limitations. First, only one type of RPR and PAPR was used in this study; hence, it may be necessary to extend this analysis to multiple types of the particulate respirators. Moreover, the particulate respirator, knit cover, and towel were all unused; however, these items are typically used for long periods in the workplace. The impact of equipment deterioration on the performance of the respirator should be a subject for future investigation. Regarding the wearing method, to minimize the effect of the individual's ability to accurately fit the respirator, the subjects wore the particulate respirator while looking in a mirror; if the examiner noticed an abnormality such as a twisted strap, the subject was asked to remove the particulate respirator and re-attach it. Therefore, actual leakage rates may vary according to the individual's ability to fit it accurately. It is also important to verify the leakage rate of an actual worker who has received no advice on how to attach the equipment.

\section{Conclusion}

This study evaluated the performance of two types of respirators, RPR and PAPR, worn according to methods that contrast widely circulated recommendations. The performance of the RPR was reduced when commonly non-recommended wearing methods were adopted; however, the PAPR performance did not exhibit a significant decrease with the different wearing methods. Therefore, a PAPR is recommended for work where a replaceable or disposable particulate respirator fails to provide sufficient protection against hazardous dust substances or for workers who are unable to use a particulate respirator according to the recommended method because of the work environment or health conditions. These findings have important practical applications for the health and safety of workers exposed to hazardous dust in the workplace.

\section{Funding}

This study was funded by Industrial Disease Clinical 
Research Grants (180302-01).

\section{Conflict of Interest}

The authors declare no conflicts of interest.

\section{Acknowledgments}

We acknowledge Soft Wave Pro Co., Ltd. for helping with data aggregation work, as well as all participants, and staff members. We would also like to thank Editage (www. editage.com) for English language editing.

\section{References}

1) Japan Ministry of Health, Labour and Welfare, Labour Standards Bureau The circular notice: selection and use of a particulate respirator (released on February 7, 2005) (in Japanese). https://www.mhlw.go.jp/web/t_doc?dataId=00tc 2747\&dataType=1\&pageNo=1. Accessed June 20, 2020.

2) Occupational Safety and Health Administration [OSHA]. The OSHA respiratory protection standard in Title 29 of the Code of Federal Regulations Part 1910. 134 for General Industry. https://www.osha.gov/laws-regs/regulations/ standardnumber/1910/1910.134. Accessed June 20, 2020.

3) Shirasaka T, Ando H, Ikegami K, Ogami A (2019) A survey on methods of wearing respiratory protective equipment and awareness of respiratory protection among workers engaged in dust-generating work. Environ Occup Health Pract 1, 39-45. [CrossRef]

4) Jafari AJ, Assari MJ (2004) Respiratory effects from workrelated exposure to welding fumes in Hamadan, Iran. Arch Environ Health 59, 116-20. [Medline] [CrossRef]

5) Yamada G, Igarashi T, Sonoda H, Morita S, Suzuki K, Yoshida Y, Abe S (1998) Use of bronchopulmonary lavage for eliminating inhaled fume particles from a patient with arc welder's lung. Intern Med 37, 962-4. [Medline] [CrossRef]

6) Jp NA, Imanaka M, Suganuma N (2017) Japanese workplace health management in pneumoconiosis prevention. J Occup Health 59, 91-103. [Medline] [CrossRef]

7) Ministry of Labour Ordinance (April 25, 1979). Ordinance on Prevention of Hazards Due to Dust (in Japanese). https:// www.mhlw.go.jp/web/t_doc?dataId $=74107000 \&$ dataType $=$ 0\&pageNo=1. Accessed June 20, 2020.

8) Ordinance of the Ministry of Health, Labour and Welfare (February 24, 2005). Ordinance on Prevention of Health Impairment due to Asbestos (in Japanese). https://www. mhlw.go.jp/web/t_doc?dataId=74aa6787\&dataType $=0 \& p a$ geNo=1. Accessed June 20, 2020.

9) Japan Ministry of Health, Labour and Welfare, Labour Standards Bureau Enforcement of Cabinet Ordinance
Partially Amending Order for Enforcement of Industrial Safety and Health Act and Ministerial Ordinance Partially Amending Ordinance on Prevention of Hazards Due to Specified Chemical Substances and Ordinance on Industrial Safety and Health (released on November 20, 2016) (in Japanese). https://www.mhlw.go.jp/web/t_doc?dataId=00tc 2349\&dataType $=1 \&$ pageNo $=1$. Accessed June 20, 2020.

10) Japan Ministry of Health, Labour and Welfare, Labour Standards Bureau Ninth Comprehensive Measures to Prevent Hazards Due to Dust (released on February 9, 2018) (in Japanese). https://www.mhlw.go.jp/file/06Seisakujouhou-11300000-Roudoukijunkyokuanzeneisei bu/0000202860.pdf. Accessed June 20, 2020.

11) Tompkins BM, Kerchberger JP (2010) Special article: personal protective equipment for care of pandemic influenza patients: a training workshop for the powered air purifying respirator. Anesth Analg 111, 933-45. [Medline]

12) Lee SA, Grinshpun SA, Reponen $T$ (2008) Respiratory performance offered by $\mathrm{N} 95$ respirators and surgical masks: human subject evaluation with $\mathrm{NaCl}$ aerosol representing bacterial and viral particle size range. Ann Occup Hyg 52, 177-85. [Medline] [CrossRef]

13) Reponen T, Lee SA, Grinshpun SA, Johnson E, McKay $R$ (2011) Effect of fit testing on the protection offered by $\mathrm{n} 95$ filtering facepiece respirators against fine particles in a laboratory setting. Ann Occup Hyg 55, 264-71. [Medline] [CrossRef]

14) Coffey CC, Lawrence RB, Campbell DL, Zhuang Z, Calvert CA, Jensen PA (2004) Fitting characteristics of eighteen N95 filtering-facepiece respirators. J Occup Environ Hyg 1, 262-71. [Medline] [CrossRef]

15) Hon CY, Danyluk Q, Bryce E, Janssen B, Neudorf M, Yassi A, Shen H, Astrakianakis G (2017) Comparison of qualitative and quantitative fit-testing results for three commonly used respirators in the healthcare sector. J Occup Environ Hyg 14, 175-9. [Medline] [CrossRef]

16) Manganyi J, Wilson KS, Rees D (2017) Quantitative respirator fit, face sizes, and determinants of fit in South African diagnostic laboratory respirator users. Ann Work Expo Health 61, 1154-62. [Medline] [CrossRef]

17) Yu Y, Jiang L, Zhuang Z, Liu Y, Wang X, Liu J, Yang M, Chen W (2014) Fitting characteristics of N95 filteringfacepiece respirators used widely in China. PLoS One 9, e85299. [Medline] [CrossRef]

18) Floyd EL, Henry JB, Johnson DL (2018) Influence of facial hair length, coarseness, and areal density on seal leakage of a tight-fitting half-face respirator. J Occup Environ Hyg 15, 334-40. [Medline] [CrossRef]

19) Sandaradura I, Goeman E, Pontivivo G, Fine E, Gray H, Kerr S, Marriott D, Harkness J, Andresen D (2020) A close shave? Performance of P2/N95 respirators in healthcare workers with facial hair: results of the BEARDS (BEnchmarking Adequate Respiratory DefenceS) study. J Hosp Infect 104, 529-33. [Medline] [CrossRef]

20) Japanese Industrial Standards JIS T8150: the guidance for 
the selection, use, and maintenance of respiratory protective equipment (released on April 25, 2006) (in Japanese). https://kikakurui.com/t8/T8150-2006-01.html. Accessed June 20, 2020.

21) Japanese Industrial Standards JIS T8159: the procedure for measuring the leakage rate of respiratory protective equipment (released on February 20, 2006) (in Japanese). https://kikakurui.com/t8/T8159-2006-01.html. Accessed June 20, 2020.

22) Wu B, Leppänen M, Yermakov M, Grinshpun S (2018) Evaluation of a new instrument for aerosol quantitative fit testing. J Int Soc Respir Prot 34, 111-27.

23) Kikuzi K (1991) A study on facepiece-to-face fitting of dust respirators (Report 3): mask fitting tester. Rodo Kagaku 67, $1-8$.

24) Aiba Y, Kobayashi K, Suzuki J, Shimizu Y, Nishimura M, Sasaki N, Makino S, Utsunomiya T (1995) A questionnaire survey on the use of dust respirators among lead workers in small scale companies. Ind Health 33, 35-41. [Medline] [CrossRef]

25) Takemura $Y$, Kishimoto $T$, Takigawa T, Kojima S, Wang BL, Sakano N, Wang DH, Takaki J, Nishide T, Ishikawa K, Ogino K (2008) Effects of mask fitness and worker education on the prevention of occupational dust exposure. Acta Med Okayama 62, 75-82. [Medline] 